\title{
Melting of reycled crust responsible for the Gutenberg discontiuity
}

\author{
JIA LIU* ${ }^{* 1,4}$, NAOTO HIRANO ${ }^{2}$, SHIKI MACHIDA ${ }^{3}$, QUNKE
}

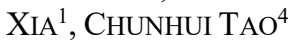

${ }^{1}$ Key Laboratory of Geoscience Big Data and Deep Resource of Zhejiang Province, School of Earth Sciences, Zhejiang University, Hangzhou, China.

liujia08@ustc.edu.cn, qkxia@zju.edu.cn

${ }^{2}$ Center for Northeast Asian Studies, Tohoku University, Japan.nhirano@tohoku.ac.jp

${ }^{3}$ Chiba Institute of Technology, Ocean Resources Research Center for Next Generation, Japan.

shiki.machida@p.chibakoudai.jp

${ }^{4}$ Key Laboratory of Submarine Geosciences, Second Institute of Oceanography, MNR. China

taochunhuimail@163.com

A discontinuity in the seismic velocity associated with the lithosphere-asthenosphere interface, known as the Gutenberg discontinuity, is enigmatic in its origin. While partial mantle melts are frequently suggested to explain this discontinuity, it is not well known which factors critically regulate the melt production. Here, we report geochemical evidence showing that the melt fractions in the lithosphereasthenosphere boundary were enhanced not only by accumulation of compacted carbonated melts related to recycled ancient marine sediments, but also by partial melting of a pyroxene-rich mantle domain related to the recycled oceanic eclogite/pyroxenites. This conclusion is derived from the first set of $\mathrm{Mg}$ isotope data for a suite of young petit-spot basalts erupted on the northwest Pacific plate, where a clearly defined $\mathrm{G}$ discontinuity exists. Our results reveal a specific linkage between the $\mathrm{G}$ discontinuity beneath the normal oceanic regions and the recycling of ancient subducted crust and carbonate through the deep Earth. 